\title{
Endoscopic Total Thyroidectomy: Report of Two Cases
}

\author{
MM AZIZ $^{\mathrm{a}}$, MA W KHAN ${ }^{\mathrm{b}}$, S ISLAM ${ }^{\mathrm{c}}$
}

\begin{abstract}
Summary:
Two patients (one male and one female) recently under went total thyroidectomies using a standard laparoscope at the department of surgery, Bangabandhu Sheikh Mujib Medical University (BSMMU), Dhaka. Three ports (one mid line and two laterals) were employed and a harmonic scalpel was used for the dissection. To the best of our knowledge, there was no report of endoscopic total thyroidectomy from Bangladesh. Both patients were fed on the first post operative day. They were discharged
\end{abstract}

\section{Introduction:}

Solitary thyroid nodule is one of the common problems encountered in surgical practice. About 15 $\%$ of the solitary thyroid nodules subsequently turned out to be thyroid carcinoma requiring total thyroidectomy and another $30-40 \%$ to be follicular adenoma $^{1}$. An operation on the thyroid gland in conventional method whether due to a benign or a malignant lesion requires a long incision in front of the neck and always matter of distress to the young patients who are the most common sufferers. In the recent years to address this problem lateral mini cervical incision was tried. However, endoscopic thyroidectomy through the thoracic or axillary routes was recently performed in some centre ${ }^{2}$. Demonstration of endoscopic excision of benign thyroid nodule, done recently at the live demonstration workshop of the Society of Laparoscopic Surgeons of Bangladesh by Dr. Shailesh Puntambekar, was the first endoscopic thyroid operation in Bangladesh. Subsequently, Endoscopic total thyroidectomy was performed using laparoscope in these two reported patients having

a. Dr. M Mohibul Aziz, FCPS, FRCS (Edin), FRCS (Glasgow.), Associate Professor, Department of Surgery, Bangabandhu Sheikh Mujib Medical University, Dhaka.

b. Dr. MA Wohab Khan, FCPS (Surgery), Associate Professor, Department of Surgery Bangabandhu Sheikh Mujib Medical University, Dhaka.

c. Dr. Sharmin Islam, MBBS, Resident, Department of Surgery, Bangabandhu Sheikh Mujib Medical University, Dhaka.

Address of correspondence: Dr. M Mohibul Aziz, FCPS (Surg.), FRCS (Edin), FRCS (Glasgow.), Room no -912, Block -C, Bangabandhu Sheikh Mujib Medical University, Shahabag, Dhaka.

Received: 24 April, 2007

Accepted: 13 September, 2007 between the 3rd and 4th post operative days. There was no hypocalcaemia but one patient developed temporary unilateral vocal cord palsy. Endoscopic thyroidectomy appears to be a technically feasible patient friendly modality of treatment for the selected cases of thyroid swelling in an experienced hand with excellent out come.

Key Words: Endoscopic; laparoscopic; thyroid surgery; total thyroidectomy.

(J Bangladesh Coll Phys Surg 2008; 26: 46-49)

papillary carcinoma of thyroid presented with solitary thyroid nodule.

\section{Case Report 1:}

Mr. F 36 year's old male patient presented with a swelling in front of the neck which he noticed for two weeks. There was no feature of hypo or hyper thyroidism. However, he had history of weakness and weight loss for the last 2 years. On examination his pulse was 78 per minutes and regular in rhythm. Examination revealed a firm oval nodule of $3.0 \times 2.8$ $\mathrm{cms}$ in size arising from the left thyroid lobe. Rest of the gland was normal. His TSH, FT3, FT4 were within normal limit. FNAC revealed a papillary carcinoma. His serum calcium was normal but serum creatinine was $165 \mu$ mole / L, chest x-ray showed enlarged right Para-tracheal lymph nodes and CT scan of the chest showed mediastinal lymphadenopathy. Endoscopic total thyroidectomy was done through the thoracic route with 30 degree telescope. Even though, both his recurrent laryngeal nerves (RLN) were identified clearly and safeguarded, he developed hoarseness of voice due to temporary right RLN palsy which showed marked improvement within three weeks. Post operatively his serum calcium was normal.

He was referred to the nuclear medicine department for further management

\section{Case Report 2:}

Ms. P 16 years old female patient presented with a painless lump in front of the neck for 2 years. The swelling was gradually enlarging in size. There was no feature of hyper or hypothyroidism. On examination, she had solitary thyroid nodule about 3 X $2.5 \mathrm{cms}$ in size arising from the left lobe of the 
thyroid. There was no palpable cervical lymph node. Her TSH, FT3, FT4 were within normal limit. FNAC revealed papillary carcinoma. She also under went endoscopic total thyroidectomy via thoracic route using 30 degree telescope. She was offered oral liquid within 8 hours and solid diet from the $1^{\text {st }}$ post operative day and she was discharged on the $3^{\text {rd }}$ post operative day. Post operatively there was no hypocalcaemia and no recurrent laryngeal nerve palsy. She was also referred to the nuclear medicine department for further management

\section{Operative Procedure:}

Under general anesthesia each patient was placed supine with neck extended as it is done for the open thyroidectomy. Three ports were used, one $10 \mathrm{~mm}$ in the mid line $5 \mathrm{cms}$ below the supra-sternal notch for the telescope and two $5 \mathrm{~mm}$ lateral ports $5 \mathrm{cms}$ lateral to the midline on either side just below the clavicle for the working instruments. Initially, the sub platismal plane was created with a pair of hemostat and Tubb's dilator (the instrument used for closed

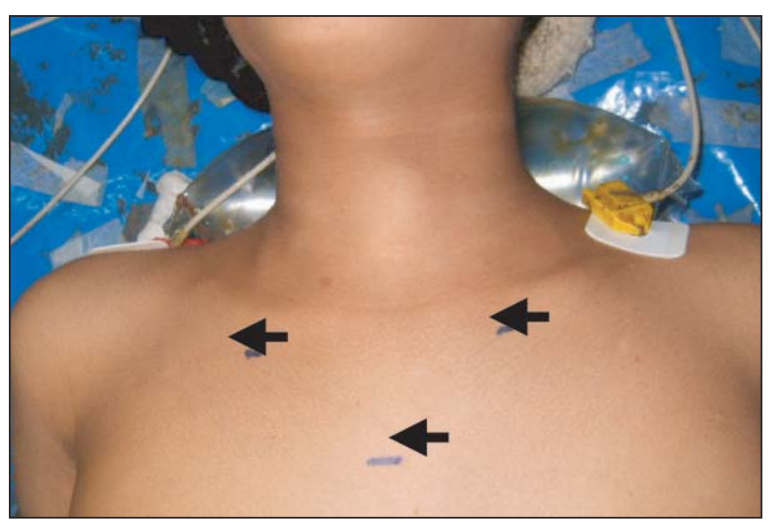

Fig.-1: Neck position and port site marked. (in thyroid nodule)

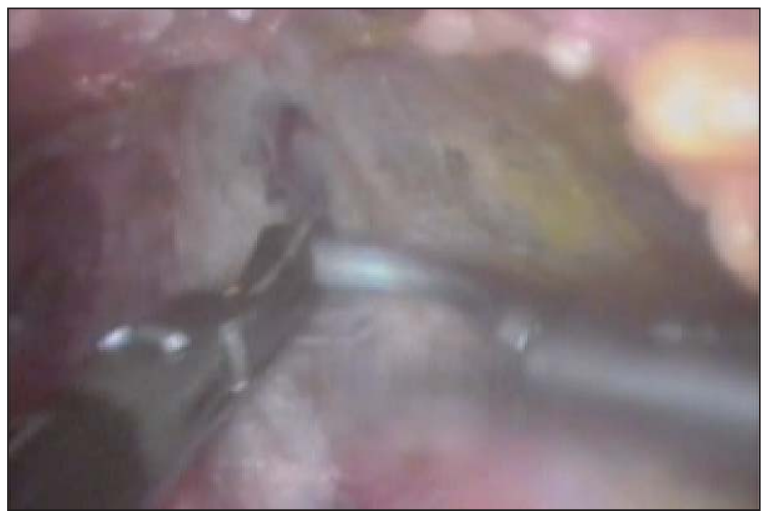

Fig.-3: Sub platismal dissection mitral commissurotomy); later with a harmonic scalpel. This space- extended from the hyoid bone above to the clavicles below and laterally to the lateral borders of the sterno-cleido-mastoid muscles. The investing layer of the cervical fascia was divided in the mid line. Strap muscles retracted laterally to expose the gland. The lower pole of the involved thyroid lobe was pushed up and all vessels were divided with a harmonic scalpel. The recurrent laryngeal nerve was identified and lateral and posterior part of the gland was mobilized protecting the parathyroid glands and recurrent laryngeal nerve. The main trunk of inferior thyroid artery was preserved to maintain the blood supply to the parathyroid. Then the superior thyroid pedicle was divided with the harmonic scalpel. Once the involved lobe was completely mobilized, the other lobe was mobilized in the same way. The specimen was put in a plastic bag and removed through the 10 $\mathrm{mm}$ port which was stretched a bit to facilitate the delivery. The wound was irrigated with normal saline, hemostasis was checked and ports were closed after keeping a drain.

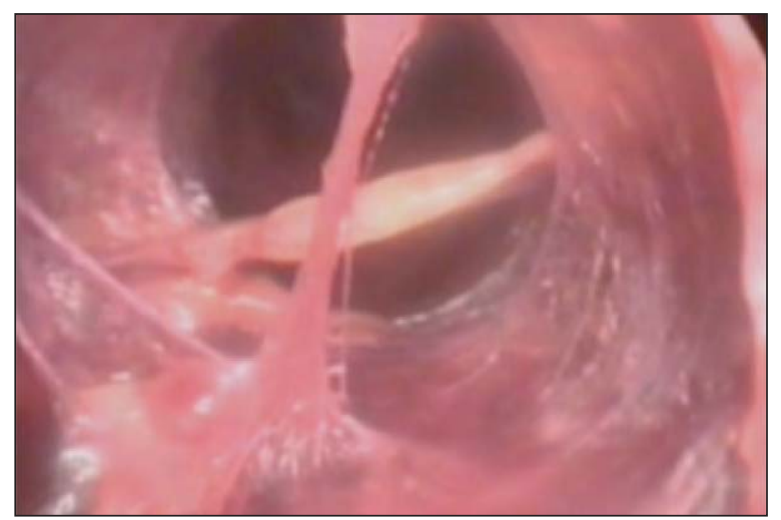

Fig.-2: Creation of sub-platismal space

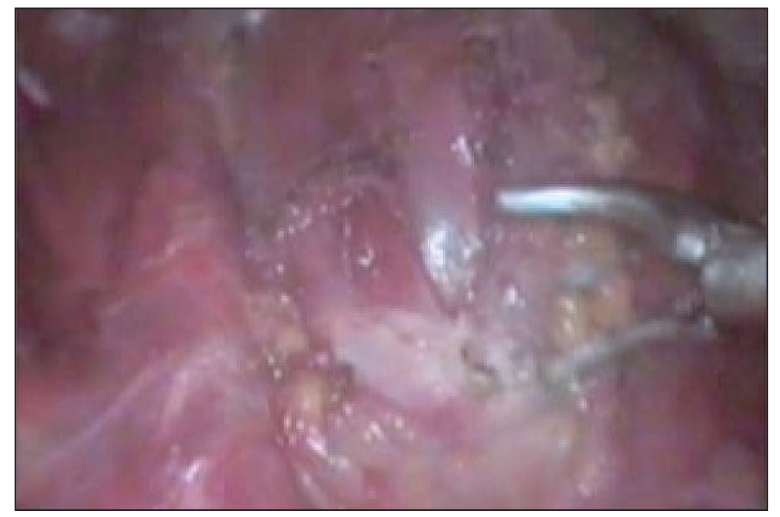

Fig.-4: Strap muscles retracted. 


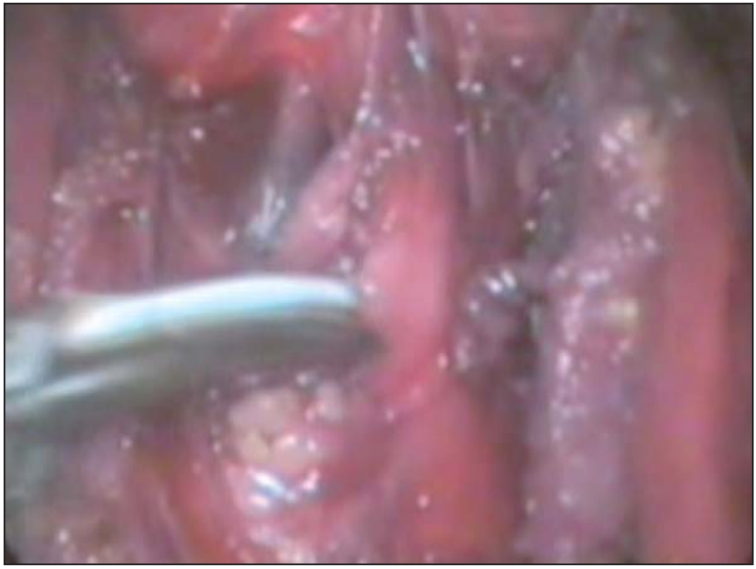

Fig.-5: Inferior thyroid artery with parathyroid gland

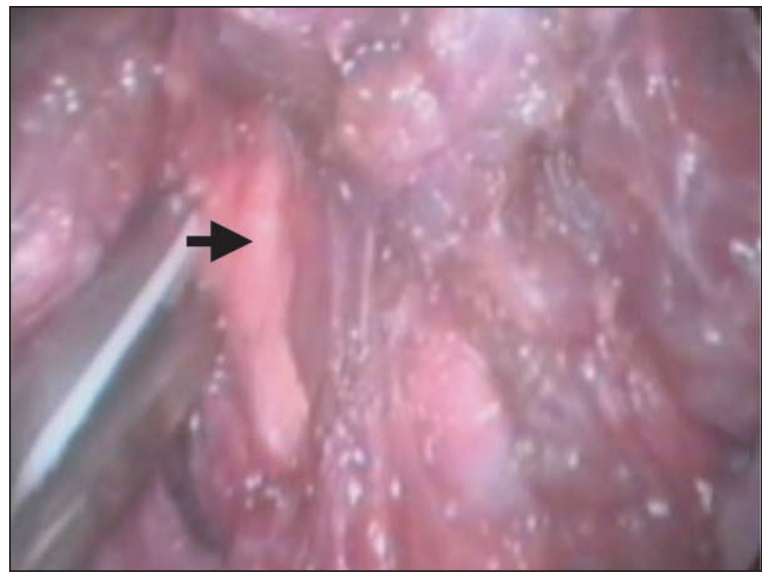

Fig.-7: Right recurrent laryngeal nerve.

\section{Discussion:}

Endoscopic Thyroidectomy can be done through the cervical ports or via extra-cervical ports ${ }^{2}$. Both our patients had operation through the thoracic ports. In thoracic ports the scars are usually hidden under the garments. The sub -platismal plane is relatively avascular so creation of the sub-platismal space did not pose any difficulty. Moreover, the use of the Tubb's dilator and the harmonic scalpel made it much easier. Carbon-di -oxide insufflations at 5-10 $\mathrm{mm}$ of $\mathrm{Hg}$ pressure was used for the flap lifting and maintaining the working space. Although, skin traction could be used ${ }^{3}$ but it was felt that it might give unnecessary scar in the neck. After the lifting of the flap, rest of the operation was essentially the same as the conventional open thyroidectomy.

It was felt that the magnified view obtained during the endoscopic surgery would make the identification

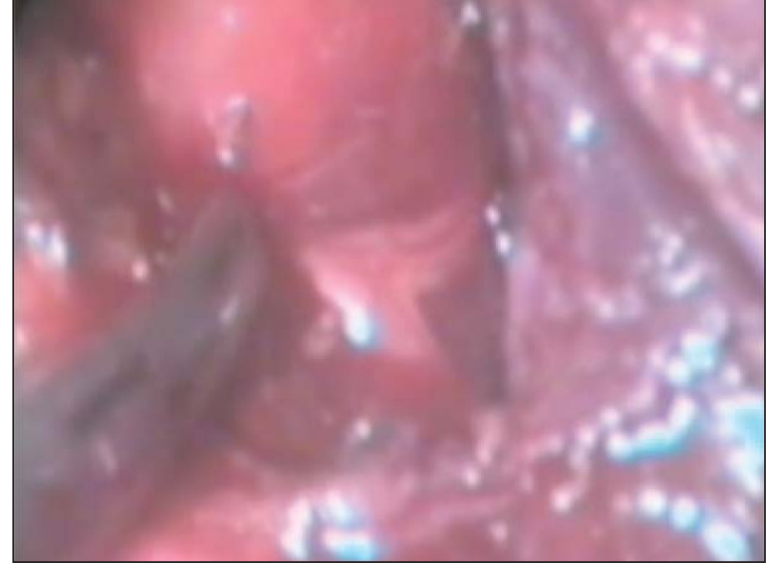

Fig.-6: Left recurrent laryngeal nerve

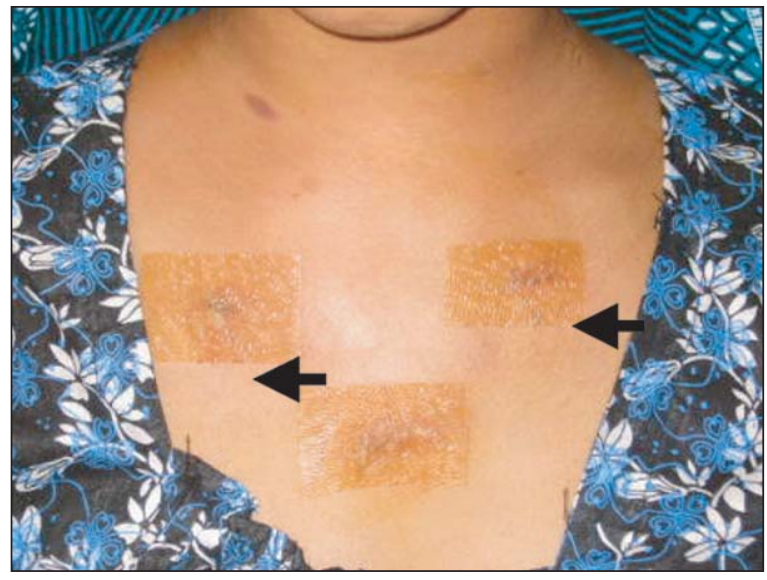

Fig.-8: Port site after completion of operation.

of parathyroid glands and recurrent laryngeal nerves much easier. The main trunk of Inferior thyroid artery was protected to keep the blood supply of the parathyroid glands. The size of the thyroid nodules in both the patients were about $3 \mathrm{cms}$. In most of the series, endoscopic thyroidectomy was done for the selected group of thyroid patients where the size of the nodule was less than $3 \mathrm{cms}$, without any history of neck surgery, neck irradiation and evidence of thyroiditis ${ }^{4}$. Most of the authors reserved this for benign cases ${ }^{2}$. But both of the reported patients had malignancy. Here, total thyroidectomy was performed without any difficulty. Management of the lymph nodes in thyroid carcinoma may be an argument against endoscopic surgery but it was felt that an expert surgeon should be able to manage those cases endoscopically. Port site deposits may be another argument but to reduce that, the specimens 
were removed within a plastic bag. Further study and long term follow up is needed to see whether this produce any significant problem or not.

The operation time for the first case was 240 minutes but for the second case 180 minutes. It is expected that the operation time would reduce further with experience.

None of the patients had any features of hypoparathyroidism although the incidence of hypoparathyroidism in total thyroidectomy ${ }^{5}$ may be as high as $33 \%$. Even though, in every case both the recurrent laryngeal nerves (RLN) were identified during surgery, first patient had temporary RLN palsy which showed marked improvement with in three weeks of operation. The over all incidence of RLN palsy is quite low but the incidence varies quite widely with the type of surgery. In patients with total thyroidectomy the temporary and permanent RLN palsy may be as high as $13.6 \%$ and $9 \%$ respectively 6. Most important measure to preserve the RLN is to identify the nerve during surgery and where not possible intra-parenchymal dissection or subtotal excision is advocated by some authors ${ }^{6}$.

In this series, none of the patients required any blood transfusion during surgery. Both patients required only one dose of pethedine. Both were satisfied with the post operative cosmetic appearance.

\section{Conclusion:}

Endoscopic total thyroidectomy for carcinoma of thyroid appears to be a technically feasible patient friendly modality. However, a dedicated surgical team and technical supports are essential. Long term follow up with a larger series is necessary to validate our present result.

\section{References:}

1. Krukowski ZH. The thyroid gland and the thyroglossal tract. In: Russell RCG, Williams NS and Bulstrode CJK (editors). Baily and Love's Short Practice of Surgery. 24th edition. London: Arnold, 2004; P, 776- 804.

2. Chowbey PK, Soni V, Khullar R, Sharma A, Baijal M. Endoscopic neck surgeryJ Min Access Surg 2007; 3: 3-7. .

3. Ambrosi A, Fersini A, Tartaglia N, Prete FP, Natale F, Lorusso G, Giannone N, Samele F, Neri V. Video assisted thyroidectomy with minimally invasive central cervicotomy: initial experience in an endocrine surgery division. Chir Ital. 2006 Sept-Oct; 58(5): 549-56.

4. Sebag F, Palazzo FF, Harding J, Sierra M, Ippolito G, Henry JF. Endoscopic lateral approach thyroid lobectomy; safe evolution from endoscopic parathyroidectomies. World J Surg. 2006 May; 30(5): 802-5.

5. Islam KMT. Fluctuation of serum calcium level after thyroidectomy and rationality of calcium supplementation. Dissertation , BCPS, 2005; 120-130.

6. Avtac B, Karamercan A. Recurrent laryngeal nerve injuries and preservation in thyroidectomy. Saudi Med J. 2005 Nov; 26(11): 1746-9. 